\title{
Educating the Cosmopolitan Citizen in Confucian Classical Education in Contemporary China
}

\author{
Canglong Wang \\ University of Hull
}

Abstract: This article explores the conceptualization of cosmopolitan citizen and the relevant teaching practice in the emerging Confucian classical education in contemporary China. It addresses two aspects. First, the cosmopolitan orientation of the cultural subject constructed in the theory of classics-reading education is embedded in the presupposition of common humanity and universal wisdom. Based on this, Confucian classical education claims to transcend the boundaries among nation-states and commits to promoting the communication and integration between Chinese and western cultures. Second, in the case study of Yiqian School, the image of cosmopolitan citizen flags up the dimension of ethical virtue, in particular, civic quality. The empirical discussion also shows the contradictions in practicing the method of memorization. The article reaches the argument that the renewal of Confucian classical education demonstrates a cosmopolitan orientation in citizen cultivation, this is not contradictory to but reinforcing with the intertwined nationalist emotions and identities.

Keywords: Confucian revival; classical education; cosmopolitan citizen; national identity; civic quality

\section{INTRODUCTION}

Cosmopolitanism is a conceptualization that can be traced back to ancient Greek and Roman philosophies and is widely discussed in Stoicism and cynicism work. Today, the dynamic of globalization and the resulted cross-border flows of capital, people and information have re-engineered this idea to signify an interrelated political community beyond nation-states (Hull et al., 2010). As Appiah (2006) and other scholars (e.g., Hansen, 2010) conceived it, cosmopolitanism has expanded the notion of citizenship and created a new space 
of community, whether digital or material, where the subject practices novel forms of civic engagement. Cosmopolitan citizenship breaks through the boundaries among nation-states and blurs the relationship between private and public domains (Stevenson, 2003; Turner, 2006). It particularly highlights the cultural dimension of citizenship and the critical imaginations about the relationship between self and others (Hermes 2006). In this sense, the concept of cosmopolitan citizenship requires nurturing habits of mind (Hull et al., 2010), and refers to an aesthetic, ethical and moral subject (Hansen, 2010). It can be said that the idea of cosmopolitan citizenship magnifies the formulation of cultural identity, decouples it from nation-states, national cultures and national societies, and opens the space for accommodating universal values (Stevenson, 2003).

Education plays a pivotal role in the cultivation of cosmopolitan citizens. Hayden (2017, p. 254) differentiates two types of cosmopolitan education: the results-oriented form "that consists of strong cosmopolitanism, empirical morality and structural cosmopolitanism," and the process-centric kind "that consists of moderate cosmopolitanism, deliberative morality and dispositional cosmopolitanism." Using Socrates and the Stoics for reference, Nussbaum (2017) proposes three core capacities for cosmopolitan education: (1) to examine one's self, history and world in a critical way, (2) to develop narrative imagination that facilitates the improvement of one's empathy, tolerance and acceptance of otherness, and (3) to see oneself as a cosmopolitan, this bridging the cognitive (self-examination) and affective (narrative imagination) elements. Following the scenario, Nussbaum argues for an other-oriented curriculum in educating cosmopolitans, one that, in terms of Papastephanou (2003, p. 71), "regards the teaching of other civilisations not as concession and charity but as simultaneously duty and benefit for the local culture." Nussbaum's justification of teaching about cosmopolitanism is actualized by two ways: one is to identify cosmopolitan morality as a time-honored ideal that reminds us of our human commonality; and the other is to discern cosmopolitanism as an empirical and experiential fact associated with contemporary temporary and spatial shortcuts (Nussbaum, 1996). The implicit assumption of what Nussbaum terms 
"cosmopolitan education" is that "patriotism is ethically neutral whereas cosmopolitanism is ethically charged, and hence education ought to make the most of this positive ethical relevance" (Papastephanou 2003, p. 73).

This article aims to explore the connotation of cosmopolitanism and its role in citizen formation in the context of Confucian education in contemporary China. In general, Confucianism supports cosmopolitanism as both "celebrate(s) the idea of intermingling: cultural exchanges, economic integration, and political sharing between ethnic and cultural groups" (He 2004, p. 114). However, Confucianism embraces a different version of cosmopolitanism from its ancient Greek counterpart. Cosmopolitanism, as Socrates or Stoics argued for, is largely individualistic, elitist and polis-centric. Nussbaum (1996, p. 15) capsules this orientation as "strong universalism", which acknowledges the worldwide nature and universality of moral obligations, and requires "a kind of exile-from the comfort of local truths, from the warm, nestling feeling of patriotism, from the absorbing drama of pride in oneself and one's own." Confucian interpretation of cosmopolitanism, in contrast, is aligned with "rooted cosmopolitanism" (Appiah 2005), which "takes into account localised and cultural contexts that underpin, determine and give value to social practices" (Tan 2019, p. 70). For example, in her unpacking of Mencius' extension of moral feelings, Charlene Tan (2019) indicates that Confucian cosmopolitanism is featured with an expansion of family love to the world community to achieve universal harmony.

The reappearance of Confucian classical education, as one essential component of Confucian revival, is a striking occurrence in contemporary China. Since the mid-1990s, Confucian education has been rejuvenated throughout the country and demonstrated a trend of diversification in educational theories, methods and approaches (Wang, 2018). Among the varieties of Confucian education, the most influential one is broadly called "classics-reading education" (dujing jiaoyu), which is the focus of this research. Wang Caigui, a Confucian scholar and an educator from Taiwan, had been promoting this particular type of Confucian education in Mainland China since the early 2000s. He proposed a unique educational theory that has maintained a far-reaching influence on 
nascent Confucian schools and study halls (xuetang). It is true that the revival of Confucian education is always sophisticated with complex nationalist sentiments, for instance, national superiority and inferiority (Wang, 2016). However, Confucian revival also presents a distinct orientation of cosmopolitanism beyond national concerns, but this has yet to receive attention from researchers.

In order to fill this gap, this article is committed to exploring the influence of cosmopolitanism on citizen making in Confucian education. How is the term "cosmopolitanism" and its civic significance conceptualized in the theoretical discourse of Confucian classical education? What teaching practices are applied in Confucian schooling? Responding to these research questions, the following sections will first uncover the conception of "cosmopolitan citizenship" in the theory of classics-reading education, and then describe the teaching and learning practices in a characteristic Confucian classical school, where I did fieldwork.

\section{COSMOPOLITANISM AND ITS CIVIC SIGNIFICANCE IN THE THEORY OF CLASSICS-READING EDUCATION}

To uncover the meaning of cosmopolitan citizenship in the context of Confucian classical education, it is necessary to go directly into the theory of classics-reading education proposed by Wang Caigui to see how the terminology is articulated. The term "citizen" rarely appears in Wang Caigui's theoretical discourse, but some civic elements, such as responsibility, ethical virtue and action (Guo, 2016), frequently come to the force and are addressed from the cultural and historical perspectives. Wang Caigui emphasized that contemporary Chinese citizens should not cast off their responsibility to revitalize or carry forward Chinese traditional culture, arguing that the sense of national and cultural responsibility is derived from the common humanity that transcends racial, ethnic and national boundaries. A person, regardless of his nationality, would generate aspirations for the eternal and universal wisdom and take actions to absorb it as long as he sincerely follows his conscience (liangzhi) and investigates his inner heart-mind (xin). Thus, the motivated responsibility does involve the national culture. But since the presupposed common humanity goes 
beyond the nation-state, it also remains open to cultural essentialities of all nations in the world and aims at promoting cultural communication.

Based on the foundation of common humanity, Wang Caigui elaborated on the significance of classical education. He stated that classics, no matter which ethnic or national groups they come from, are the crystallization of universal human wisdom. Consistent with the law of human nature, they enjoy the privilege to cultivate one's sound attitude towards life and to achieve one's personality with cultural capability and political integrity (Wang, 2014). Therefore, regarding humanity as the common ruler, Wang Caigui emphasized that any culture in the world, regardless of which nation-state it belongs to, is worth learning as they conform to human nature (Ibid).

The theory of classics-reading education assumes the decoupling of nationalism and demonstrates a cosmopolitan orientation. It is not just the nation/state, but also the world/human that lies in the core. Cosmopolitanism, associated with the thesis of human commonality and cultural universalism, is extensively distributed in the theoretical discourse on Confucian classical education. As classics are conceived to contain universal truth or eternal wisdom (changli) that surpasses national boundaries, all nationalities should comply with the classic doctrines of their own and others. The eternality of classical wisdom is believed to originate from common humanity, on the premise that all humans feel and reason alike. In tandem with this, re-engaging in classics learning calls on human nature, and reading classics is proposed as the most reasonable and eternal way for this. Wang Caigui advocated an inclusive stance for cultural plurality and an individualized manner of learning that associates individual learners with the entire world and all human beings.

The cosmopolitanism espoused by classical education has exerted profound influences on the teaching and learning practice. In terms of teaching content, Wang Caigui strongly advised that students should not only read Chinese classics, but also engage in learning western great works, including English, German and Sanskrit classics. Additionally, he suggested that a child listen to world-famous 
music and read world-famous paintings starting from three years old. This is in accordance to humane holism, and is common to contemporary Confucian education that puts both Chinese and western classics at the center of teaching.

Mechanical memorization of classics is recommended as the principal way to cultivate cosmopolitan cultural talents in Wang Caigui's theory. This proposal is deeply embedded in the scientific discourse that clarifies human nature. According to Wang Caigui, the natural law of human development is to prioritize the development of memory, and then the capacity of comprehension. Before the age of 13 , a person has the most power to memorize whereas his ability to understand is relatively weak. Thus, the most appropriate way of education is to comprehensively develop his memory first, instead of forcing him to understand. This method involves repetitive reading and the memorization of the content of classic literature. By combining these two aspects, classical education is regarded the most coincident with human nature. On the one hand, repeated learning is assumed to take full advantage of one's memory, which is believed to be in line with the theory of children's natural growth. On the other hand, the memorized classic texts are considered as the crystallization of the eternal and universal human wisdom, and this is argued in coherence with common humanity.

Wang Caigui proposed a criterion for cultivating cosmopolitan cultural talents, that is, to recite at least 300,000 words of classics, of which 200,000 are Chinese, inclusive of Confucianism, Taoism and Buddhism, and 100,000 that are non-Chinese. Once a student, ideally before the age of 13 , completes the required memorization, he will become eligible for further training in a classical academy (shuyuan), where he will first systematically interpret the Chinese classics he has memorized, and then read extensively, the great books that have profound impacts on western culture. Given that a student finishes the two stages of training, he is assumed to have grasped a comprehensive understanding of human culture and have developed a solid foundation to contribute to the bridging of Chinese and western cultures (Wang 2014).

Drawing the sketch of the cosmopolitan civility suggested by Wang's theory, 
I come to three points. The first relates to the cultural dimension. The Confucian-inspired form of cosmopolitan citizen is essentially a cultural subject, rather than a civil or political subject, whose fundamental quality is the sophistication in both Chinese and western classics.

The second point relates to civic responsibility. The type of cosmopolitan citizen in Confucian education is endowed with dual cultural mission - he is responsible to carry forward Chinese traditional culture and he also assumes the obligation to grasp western culture and promote global cultural integration. The sense of cultural responsibility derives from his examination and interrogation upon self, whereby he involves himself with the wellbeing of common world and humankind. This further corresponds with the Confucian unremitting pursuit of "inner cultivation and exterior action" (neisheng waiwang).

The third point relates to action. Learning classics, both Chinese and western, can be understood as a cultural and civic action that is associated with the broad revival of Chinese nation and the imagined fusion of Chinese and western cultures. This cultural and civic action manifests in a private and individual form, but is also intimately connected to national and cosmopolitan concerns. Classical study generally occurs in a private space, where the learner exerts power upon himself and guides the learning performance on his own. The self-directing process not only aims to improve one's moral cultivation and ethical quality, but also works to rejuvenate the national culture and promote the global culture. This echoes the works on Asian citizenship by Lee et al. (2004) who argued that the primary distinction between East (Chinese) citizenship and West citizenship concepts is that the former stands for a person to develop a moral personality in becoming a good citizen, suggesting that the public and private virtues are difficult to divide. To sum up, cosmopolitan citizenship in contemporary Confucian classical education is theoretically imagined to be a subject of culture, responsibility, and action, requiring one to substantiate his civic identity through memorizing both Chinese and western classics. 


\section{CULTIVATING THE CONFUCIAN COSMOPOLITAN CITIZEN AT A CLASSICAL SCHOOL}

This part will navigate from Wang Caigui's theoretical explanations to the empirical descriptions of a Confucian classical school - Yiqian School ${ }^{1}$. Yiqian School, located in China's southeastern area, was a private nine-year school of compulsory education system approved by the local government. Although monitored by the local Education Bureau, the school enjoyed a comparatively independent status in curriculum provision and didactical activities. Students were taught Confucian classics, such as The Four Books and The Five Classics, and Taoist classics, such as Laozi and Zhuangzi. This is in addition to the state-stipulated courses of Chinese Language, English Language and Mathematics. Additionally,, there was one English classics session for each of the six classes every day. Both Chinese and English classics were compulsory subjects for all students, whereas the state-required subjects served a supplementary role insofar as students learnt on their own. The selection of classics was inscribed into the school's syllabus, but the head teachers of each class could exercise discretion on the classic book to teach, depending on students' overall performance. The Confucian curriculum was essentially aligned with the proposal by Wang Caigui, who compiled the classic textbooks that the school used.

I conducted fieldwork at Yiqian School in 2015, and collected data through observing the teaching activities in the classroom, interviewing teachers, students and parents, and gathering written documents. Drawing on the empirical data, I intend to disclose how the term "cosmopolitan citizenship" is conceptualized and practiced in the school context. This section will describe the pedagogies in the classroom and identify the implied contradictions in educating cosmopolitan citizens.

Confucian classical education demonstrates an explicit orientation of cosmopolitanism. It is an essential part of the broad Confucian revival and it is originated from nationalist emotions and the pursuit of national identity. This is 
not surprising, because Confucian culture itself embraced cultural universalism and conceptualization of "all-under-heaven" (tianxia) (Wang 2015). Both are connected with the notion of cosmopolitanism under the power of globalization. What is worth noting is how the idea of cosmopolitanism shapes the pedagogy of Confucian schools. The term "cosmopolitan citizen" was boldly inscribed in Yiqian School's educational goals and frequently appeared in its official syllabus (see below).

To conduct an educational experiment involving Chinese and western classical cultures, with the aim to cultivate cosmopolitan citizens who accomplish virtues and wisdom and have a thorough knowledge of both western and traditional Chinese culture. (School document, March 2015; italics by author)

As articulated by this goal, the so-called "cosmopolitan citizen" referred to a subject not of politics or jurisdiction, but of culture and morality in the context of Confucian schooling. Associating nationalism with cosmopolitanism, Yiqian School was committed to educating students to become cultural citizens who were endowed with both Chinese classical virtues and comprehensive knowledge of Chinese and western cultures. In tandem with this, the school required students to "love the family, love the teacher, love the country, love the nation, and love the human race" (school document).

The contextualized interpretation of cosmopolitan citizen, though influenced by Wang Caigui, was not directly taken from him. While Wang hardly used this definition, he repeated similar ideas in his writings and speeches. Virtues, wisdom, or knowledge of western and Chinese cultures must be seen as the essential qualities for a person to become both a citizen and a human. It is on this point that the conception of citizen is bound with universal humanity and moral cosmopolitanism in Confucian education. The term 'cosmopolitan citizen' was proposed by Liu Jintao, a teacher who once worked at Yiqian and creatively capsuled what Wang Caigui elaborated in this term. The following exhibits $\mathrm{Mr}$ Liu's reading of "citizen," which opens up a window for the conceptual complexity. He first explained the necessity of introducing the term "citizen" to 
contemporary Confucian education.

I think the positioning of classical education is too high to reach. "To set life for people," "to initiate peace and security for all ages," too far away. [...] I think the term of citizen can work as a transitional idea to improve human nature. Professor Wang Caigui said education should set the aim to enhance human nature, but this is too abstract. (Interview, schoolteacher, April 2015)

Mr Liu clarified that the notion of citizen refers to someone who had the sense of social rule, civic consciousness, and public spirit, and who assumed the responsibility to obey social rules and engage in public affairs. He capsulized all of these into the terminology "civic qualities" (gongmin suzhi).

To promote civic consciousness is strikingly important to society. Chinese culture is weak on the thinking of social morality but pays much attention to self-cultivation. As you see, Chinese people are often criticized of their low qualities when they travel abroad. This is because our traditional culture does not emphasize civic qualities. A person living in modern society is obligated to comply with social rules. He must have civic qualities. In today's China, a person should at first be a citizen who is a member of society and state. (Interview, schoolteacher, April 2015)

Moreover, he suggested that the notion of citizen should work as the foundation to be a human and the origin to cultivate students into a superior person (junzi).

Citizen is the basic personalized unit in modern society. Anyone who lives in modern society should learn the essential civic qualities. However, a superior person goes beyond this. He is not only endowed with civic qualities but also full of the glory of humanity and glamour of moral idealism. (Interview, schoolteacher, April 2015)

Mr Liu's understanding of citizen shared the commonality with Yiqian School's idea of cosmopolitan citizen and the conceptualization of citizenship (Guo, 2016). Yet, while Mr Liu drew attention to public virtues, Yiqian School emphasized ethical virtue into the proposal of cosmopolitan citizen. Looking at the two 
interpretations respectively, $\mathrm{Mr}$ Liu's conceptions are similar to the public qualities stated in political textbooks that are widely applied in today's Chinese compulsory schools (Zhao 2014), as well as in mass media discourses (Yang 2015). On the other hand, ideas in favor of morality and character are pervasive in any work on Confucianism (e.g., Wang, 2015, 2016). What is worth noting is the holistic approach of memorization through which students are expected to become moral and cultural cosmopolitans. I will go back to this point later.

The conception of a cosmopolitan citizen as primarily a moral and cultural subject in the Confucian school schemes is echoed in current scholarly discussions (see, e.g., Hansen 2010; Stevenson 2003; Tan 2019). As Hansen and other researchers argued, moral cosmopolitanism "addresses questions such as whether and how human obligations extend to people outside one's immediate circle" (Hansen et al. 2009, 588). Acknowledging a deliberative mode of communication in cosmopolitan education, Roth (2010) argues that the teaching of cosmopolitanism must center students' character or disposition and develop their competence of acting upon the motive of duty beyond national interests. Similarly, a person with civic qualities, as Mr Liu indicated, has the capacity to overcome his selfishness and self-confinement to bridge himself with other people in society and the holistic human community. The cosmopolitan citizen conceptualized by Yiqian School included the ethical aspect insofar as it flaged up the competence to continuously control one's conduct, accommodate the attitude with reflexivity, hone the will in daily life, and cultivate one's temperament through self-investigation. This is reflected in the Student Rules of Yiqian School which read, "Steel you in everyday life-this is the enterprise. Reflect on yourself in emotional experience-this is the study." This educational idea corresponds with the Confucian notion of jiaohua, which means to transform the self (hua) by education (jiao) (Billioud \& Thoraval, 2015). This point echoes a key challenge in contemporary cosmopolitan education, which as Tan (2019) indicated, is how to encourage students to expand their existing affection and obligations towards their family, community, and the rest of the world. Confucianism is argued to have the potential to address this by offering a Confucian form of cosmopolitan education that 
emphasizes students' moral imagination, instinctual responses, self-reflection and rational deliberation (Ibid).

Yiqian School prioritized the memorization of classics to educate students to become cosmopolitan citizens. In turn, this corresponds directly to the above-mentioned arguments by Wang Caigui. At the school, mechanical memorization worked as a holistic and predominant method of teaching. According to my fieldwork, the school did not offer any particular course on citizenship education. Instead, following Wang Caigui, Yiqian School arranged three classes for Chinese classics and one class for English classics every day, expecting students not only to cultivate Chinese classical virtues through familiarizing Chinese classics but also to open their eyes to the world and acquire the capability to communicate with people from western countries.

The course of English classics was the primary arena for the cultivation of cosmopolitan citizens at Yiqian School. There were six classes and 120 students in total, but only one teacher, Mr Meng, was responsible for this course. Arranged with a fully scheduled timetable, Mr Meng, a middle-aged gentleman in his forties, was busy with teaching in order to ensure one English session for each class every day. Although he was not a professional English teacher and did not graduate from university or college in English language, $\mathrm{Mr}$ Meng accumulated much experience in English learning and teaching through diligent self-study for years. Qishun Class, one of the six classes, arranged the English classics course as the first afternoon session. The learning content included the English Masterpiece Selection ${ }^{2}$, a collection by Wang Caigui, instead of the state-stipulated English textbook, which is extensively used in compulsory schools. Based on Wang Caigui's educational theory, Mr Meng and the Yiqian School believed that children should spend their time learning "high-level" English classics, and mocked the current compulsory schools as merely teaching "kid's English," a term referring to simple, superficial and trivial English with "low-level cultural values." Mr Meng repeatedly explained to students the significance of learning English and encouraged an open and tolerant attitude toward cultural plurality, emphasizing that a person must not only familiarize 
Chinese classics to be an authentic Chinese but also learn English to connect with the world. "That we learn English is to shoulder the responsibility for the world!” He stated, "Only when the world becomes better China can be better, and vice versa. English language serves as a cultural bridge to communicate with people from other countries. Many foreigners do not understand Chinese language, so we can speak English to promote their acquaintance with Chinese culture."

Mr Meng worked hard to teach students English classics, but the process was remarkably slow, according to my observations. For example, he once taught one sentence throughout two months during my fieldwork. The teaching method was like this-he played back the sentence on an audio player, and students read after it over and over again. This sentence was divided into five smaller parts. Students first repeated part by part and then followed the whole sentence. Mr Meng required all students to read the sentence a hundred times until they could recite. In the process, there were no interpretations of words, and students were not allowed to read Chinese translations either. Obviously, the mechanical approach of memorization encountered contradictions in teaching practice. First, even if students were able to fluently recite the entire English texts, it was difficult for them to recognize single words. Some students at Qishun Class were able to speak out the thorough passage speedily, but monotonously. The tone was single, no alteration of rhythm or intonation, no accentual rising, falling or stress. Second, mechanical memorization resulted in students knowing nothing about the meaning of the words or sentences in the given English extracts. They were able to recite the passage fluently presumably as the result of repeating after the audio player mechanically. Moreover, $\mathrm{Mr}$ Meng never offered literary explanations or Chinese translations, and this caused students to lack desire to understand the English. In summary, there existed a certain distance between the teaching practice of mechanical memorization and the theoretical optimism.

\section{CONCLUDING REMARKS}


The cosmopolitan orientation of the cultural subject constructed in the theory of classics-reading education is embedded on the presupposition of common humanity and universal wisdom. Based on this, Confucian classical education claims to transcend the boundaries among nation-states. Cultural universalism and humane commonality serve as the prevalent yardstick for measuring the reasonability of all types of education. That is to say, to revive classical education, whether in China or western countries, as illuminated in the theory, is fundamentally to serve its moral function of awakening and enhancing humanity. In this way, Confucian classical education breaks the nationalist ideology and embarks on a road to cosmopolitanism, aiming to nurture talents not only as Chinese citizens who take the renewal of Chinese culture upon themselves, but also as cosmopolitan citizens who assume the mission of promoting the integration of Chinese and western cultures. I argue that besides the nation-state, the world/human aspect constitutes the theoretical core of classics-reading education as well. How the cosmopolitan dimension has profoundly influenced the educational practice is reflected not only in the designated teaching content that covers both Chinese and western classics but also in the prominent adherence to the memorization-based pedagogy.

All the above were reflected in the case study of Yiqian School. First of all, the school claimed to cultivate cosmopolitan citizens through classics learning and highlighted the dimension of ethical virtue. The image of cosmopolitan citizen drawn by the school referred to a moral subject with civic qualities, for instance, the obedience to social order and the spirituality of public participation, all of which are respected as the foundation to become a true human. It deserves to note that there is no mention of civic qualities in the theory of classics-reading education. Second, the classical school adopted the memorization-based pedagogy recommended by Wang Caigui and regarded it as the fundamental approach to transform students into cosmopolitan citizens. While Wang Caigui asserted that memorization is in line with the law of human development, the actual teaching practices encountered difficulties and contradictions. 
The international literature on cosmopolitan education highlights a moral imperative upon educators and educational institutions to promote students a cosmopolitan attitude, an 'other-oriented' character, a disposition of tolerating and respecting different cultures, and the moral obligation for the word community. To a large extent, what lies at the center of cosmopolitan education is the moral and cultural form of cosmopolitanism, rather than the political or the legal. Owing to the moral inclination of cosmopolitan education, the international implications of the Confucian school case could be identified. Confucian education regards one's moral endeavor and cultural competence as the most essential to overcome restrictions of patriotism and nationalism and to become citizens of the world. Confucian virtues such as spontaneous reactions to everyday life and affective connections share much commonality with those derived from ancient-Greek such as self-examination and narrative imagination (Nussbaum, 2017). Mechanical memorization serves as a holistic approach to impart comprehensive knowledge of western and Chinese classics, insofar as to intensify learners' moral awareness of cosmopolitanism. Nonetheless, the discord between teaching theory and practice implies the potential impairment of generalizing the memorization-based pedagogy for the nurture of cosmopolitan citizen.

Against the historical context of China's rise and national rejuvenation, the renewal of Confucian classical education is often intertwined with national emotions and the pursuit of rebuilding national identities (Billioud \& Thoraval, 2015). However, in addition to national concerns, we recognize the cosmopolitan, humanistic and universalistic aspects. In view of this, the cosmopolitan citizen formulated in contemporary Confucian classical education is not a subject that negates the validity of nation-state. On the contrary, it accommodates national identity and simultaneously goes beyond it by committing to the cultural communication and integration between China and western countries.

\section{AUTHOR INFORMATION}

Canglong Wang is lecturer in Chinese Studies at the University of Hull. He was 
recently awarded Ph.D. in sociology at the University of Edinburgh. His work explores the cultural, social and political dynamics in the making of Confucian citizens in contemporary China, both empirically and theoretically. His publications appeared in both English and Chinese peer-reviewed journals, for instance, Journal of Chinese Political Science, China Perspectives, Sociological Review of China, and others. His email address is honghugaoxiang@163.com.

\section{REFERENCES}

Appiah, K. A. 2005. The Ethics of Identity. Princeton: Princeton University Press.

_-_ 2006. Cosmopolitanism: Ethics in a World of Strangers. New York: W. W. Norton.

Billioud, Sebastien, and Joel Thoraval. 2015. The Sage and the People. New York: Oxford University Press.

Guo, Zhonghua. 2016. Gongmin Shenfen de Hexin Wenti (The Core Issues of Citizenship). Beijing: Central Compilation \& Translation Press.

Hansen, D. T. 2010. Cosmopolitanism and Education: A Review from the Ground. Teachers College Record 112(1): 1-30.

Hansen, D. T., et al. 2009. Education, Values, and Valuing in Cosmopolitan Perspective. Curriculum Inquiry 39(5): 587-612.

Hayden, Matthew. 2017. The Process Matters: Moral Constraints on Cosmopolitan Education. Journal of Philosophy of Education 51(1): 248-66.

He, B. 2004. Confucianism versus Liberalism over Minority Rights. Journal of Chinese Philosophy 31(1): 103-23.

Hermes, Joke. 2006. Citizenship in the Age of the Internet. European Journal of Communication 21(3): 295-309.

Hull, Glynda A., Amy Stornaiuolo, and Urvashi Sahni. 2010. Cultural Citizenship and Cosmopolitan Practice. English Education 42(4): 331-67.

Lee, W.O. et al. 2004. Citizenship Education in Asia and the Pacific. New York: Springer Science+Business Media.

Nussbaum, Martha. 1996. Patriotism and Cosmopolitanism. In For Love of Country: Debating the Limits of Patriotism, ed. M. Nussbaum and J. Cohen, 2-20. Boston: Beacon Press. 
- — - 2017. Education for Citizenship in an Era of Global Connection. In The Evolution of Liberal Arts in the Global Age, ed. P. Marber and D. Araya, 213-25. New York: Routledge.

Papastephanou, Marianna. 2003. Arrows Not Yet Fired: Cultivating Cosmopolitanism Through Education. Journal of the Philosophy of Education 36(1): 69-86.

Roth, Klas. 2010. Good Will: Cosmopolitan Education as a Site for Deliberation. Educational Philosophy and Theory 43(3): 298-312.

Stevenson, Nick. 2003. Cultural Citizenship in the 'Cultural' Society. Citizenship Studies 7(3): 331-48.

Tan, Charlene. 2019. Mencius' Extension of Moral Feelings. Ethics and Education 14(1): 70-83.

Turner, Bryan. 2006. Classical Sociology and Cosmopolitanism. The British Journal of Sociology 57(1): 133-51.

Wang, Caigui. 2014. Dujing Ershi Nian (Two Decades of Reading Classics Education). Beijing: Zhonghua Book Company.

Wang, Canglong. 2015. Confucianism and Citizenship. In Theorizing Chinese Citizenship, ed. Z. Guo and S. Guo, 49-81. New York: Lexington Books.

_-_ 2016. Individuality, Hierarchy, and Dilemma. Journal of Chinese Political Science 21: 435-52.

——_. 2018. Debatable 'Chineseness'. China Perspectives (4): 53-64.

Yang, Guobin. 2015. China's Contested Internet. Copenhagen: NIAS Press.

Zhao, Zhenzhou. 2014. Pedagogisation of Nation Identity through Textbook Narratives in China: 1902-1948. Citizenship Studies 18(1): 99-112.

\section{NOTES}

1 This is a pseudonym. All informants in this part are anonymized and are replaced with pseudonyms for the sake of ethical concerns.

2 The selection contains various types of work inclusive of written literature, speeches, poems and philosophical essays, which have remarkably influenced the western world. 